\title{
Proportion of Maternal Near-Miss and Its Determinants among Northwest Ethiopian Women: A Cross-Sectional Study
}

\author{
Mengstu Melkamu Asaye \\ Women and Family Health Department, School of Midwifery, College of Medicine and Health Sciences, University of Gondar, \\ P.O. Box 196, Ethiopia
}

Correspondence should be addressed to Mengstu Melkamu Asaye; mengstum@gmail.com

Received 13 September 2019; Revised 28 January 2020; Accepted 24 February 2020; Published 18 March 2020

Academic Editor: Samir Hamamah

Copyright (C) 2020 Mengstu Melkamu Asaye. This is an open access article distributed under the Creative Commons Attribution License, which permits unrestricted use, distribution, and reproduction in any medium, provided the original work is properly cited.

\begin{abstract}
Background. Life-threatening situations might arise unexpectedly during pregnancy. Maternal near-miss can be a proxy for maternal death and explained as women who nearly died due to obstetric-related complications. It is recognized as the predictor of level of care and maternal death. Maternal near-miss evaluates life-threatening pregnancy-related complications, and it directs the assessment of the quality of obstetric care. Objective. To determine the proportion and factors associated with maternal near-miss at maternity wards at the University of Gondar Referral Hospital, Northwest Ethiopia, 2019. Methods. A cross-sectional study design was carried out from March 1 to June 20, 2019, using WHO criteria for maternal near-miss at the University of Gondar Referral Hospital. The data are from the interviews and review of 303 systematically selected participants' medical files at maternity wards. Bivariate and multivariable logistic regression analyses were performed to analyze factors associated with maternal near-miss, including estimation of crude and adjusted odds ratios and their respective $95 \%$ confidence intervals and $p$ value less than 0.05 through SPSS version 20. Result. The study revealed that the proportion of maternal nearmiss was found to be $15.8 \%(95 \% \mathrm{CI}=11.9 \%-20.1 \%)$. In the adjusted analyses, maternal near-miss was significantly associated with low $(\leq 1000 \mathrm{ETB})$ monthly income $(\mathrm{AOR}=399 ; 95 \% \mathrm{CI}=1.65,9.65)$, seven or more days of hospital stay $(\mathrm{AOR}=5.43 ; 95 \%$ $\mathrm{CI}=2.49,11.83)$, vaginal bleeding $(\mathrm{AOR}=2.75,95 \% \mathrm{CI}=1.17,6.47)$, and pregnancy-induced hypertension $(\mathrm{AOR}=5.13 ; 95 \%$ $\mathrm{CI}=2.08,12.6)$. Conclusion and Recommendation. The near-miss proportion was comparable to that in the region. Associated factors were low monthly income, seven or more days of hospital stay, vaginal bleeding, and pregnancy-induced hypertension. Thus, giving attention on early identification and treatment of these potential factors can be the opportunity in the reduction of maternal morbidity and mortality.
\end{abstract}

\section{Introduction}

Maternal near-miss (MNM) refers to a situation where a women who nearly died but survived from a comprehensive range of life-threatening obstetric complication [1] that occurred during pregnancy, child birth, or within 42 days of termination of pregnancy [2].

According to WHO criteria, maternal near-miss is a sign of organ dysfunction that follow life-threatening conditions and it enables the assessment of the quality of care provided to pregnant women [3]. The inclusion criteria for maternal near-miss are categorized in three areas: clinical, laboratory, and management-based criteria. The reason is that these identification criteria may be used in a comparable way across the settings and over time. It is important to understand the process of care that the patient has undergone in order to improve the quality of care, and its applicability depends on the local context [4].

Developing countries account for approximately $99 \%$ $(302,000)$ of global maternal deaths, and Sub-Saharan Africa alone accounts for roughly $66 \%(201000)$ to this death [5]. The magnitude also varies among different countries and regions depending on the health care quality and availability [6]. The number of maternal death is high worldwide. This death might be associated with inadequate and poor quality of health care services. Thus, identifying the potential factors 
that leads to severe maternal life-threatening complications is necessary [7].

We can prevent maternal death through utilization of the near-miss data. Thus, the mother that survives a near-miss can provide more comprehensive information when reviewing maternal death cases. So it is a better predicate for preventive planning [8], and it is a useful means to improve the quality of obstetric care especially in low-income countries.

In developing countries, about $75 \%$ of the women were in a critical condition upon arrival. Availability, accessibility, cost of health care, and behavioral factors play an important role in the utilization of maternal health services [2]. Maternal near-miss events were associated with postpartum hemorrhage, sever preeclampsia, eclampsia, sepsis or severe systematic infection, ruptured uterus, and septic abortion $[9,10]$. But in the current study, the main approaches to the reduction of maternal near-miss and maternal deaths are emergency obstetric care, skilled care by skilled birth attendants, and unmet obstetric need [2]. Studying maternal near-miss allows the assessment of quality interventions, identifies the health system failures, and provides alternative strategies to reduce maternal mortality [11]. Delays in initiating timely and adequate treatment for obstetric complications were a major factor to develop maternal near-miss $[12,13]$.

The pregnancy-related mortality ratio, in Ethiopia, is estimated to be approximately 412 death/100,000 live birth according to $2016 \mathrm{EDH}$ [14]. One target of SDG is to achieve a reduction of global maternal mortality ratio to less than 70 per 100,000 live births by 2030 [15]. To achieve this goal and solve the problem, respectively, we have to review both maternal mortality and maternal near-miss cases. The present study is aimed at assessing the proportion of maternal near-miss and factors associated with it at Gondar Tertiary Hospital.

\section{Methods}

2.1. Study Design and Period. An institution-based crosssectional study design was employed at the University of Gondar Referral Hospital from March 1 to June 20, 2019.

2.2. Setting. The study was conducted at the University of Gondar Referral Hospital, maternity wards. It is located in the North Gondar administrative zone, in Amhara region, $727 \mathrm{~km}$ Northwest of Addis Ababa and $175 \mathrm{~km}$ far from Bahirdar. Currently, Gondar town has one tertiary hospital and five health centers. The hospital provides service for 5-7 million people of the north Gondar neighboring zones. The average annual birth rate at the University of Gondar Referral Hospital is 9600 deliveries with 800 births each month.

2.3. Source Population. All pregnant women who were in labor, delivered or aborted, or within 42 days of postpartum period and admitted in maternity wards at Gondar Referral Hospital.
2.4. Inclusion Criteria. All pregnant women who came to the hospital due to early complication of pregnancy including abortion, ectopic pregnancy, and molar pregnancy and patients presenting care in labor, delivery, or postnatal units within 42 days of delivery were included.

2.5. Exclusion Criteria. Women with obstetric near-miss complications due to incidental or accidental causes and those who were revisiting (within data collection time) and unable to respond or seriously ill at interview time were excluded.

2.6. Sample Size Determination. The sample size was calculated by using the following assumptions.

$\mathrm{Z} \alpha / 2=$ confidence level at $95 \%=1.96$, margin of error $(d)=5 \%$, and prevalence of maternal near - miss $=23.3 \%$ [11]

$$
n=(\mathrm{Z} \alpha / 2)^{2}(1-p) / d^{2}=(1.96)(1.96)(0.233)(0.767) /(0.05)
$$

$(0.05)=275$ and $10 \%$ nonresponse rate; the final sample size was 303 women

2.7. Sampling Procedure. The calculated sample size was proportionally allocated to each four maternity wards based on the previous consecutive five-month average monthly client flow of the units which were obtained by referring client registration log books. The average monthly client flow for maternity 1,2, and 3 and gynecology ward were 800, 500, 310 , and 400 , respectively. A total of 2010 women were booked. The study participants were selected by using a systematic random sampling technique among women who visited Gondar Tertiary Hospital during the data collection period. The first study participant was selected by a lottery method. I compute $K^{\text {th }}$ for each ward, and it ranges from 1.2 to 2.6 ; then, every $3^{\text {rd }}$ women were selected during the study period.

2.8. Operational Definitions. Maternal near-miss: a woman who nearly died but survived a complication that occurred during pregnancy, childbirth, or within 42 days of termination of pregnancy according to WHO criteria (if the woman full fill one criteria) [3].

Maternal mortality: death of a woman while pregnant or within 42 days of termination of pregnancy, irrespective of the duration and the site of the pregnancy, from any cause related to or aggravated by the pregnancy or its management, but not from accidental or incidental causes [16].

Delay of the decision to seek care: The time taken greater than one hour in deciding to seek care after the onset of labor.

Delay of reaching health facility: a woman is unable to arrive within one hour of travelling to reach the health facility by foot.

Delay of receiving appropriate care: a woman did not get an emergency obstetric care within the first five minutes of arrival to health facility.

Delays to intuitional delivery: at least one or more delay from the three delay model [17].

Income: refers to total household income. 
TABLE 1: Sociodemographic characteristics of study participants at the University of Gondar Referral Hospital, Northwest Ethiopia, June, $2019(N=303)$.

\begin{tabular}{|c|c|c|c|}
\hline Variables & & Frequency $(n)$ & Percent (\%) \\
\hline \multirow{3}{*}{ Age } & $\leq 20$ & 44 & 14.5 \\
\hline & $21-34$ & 228 & 75.2 \\
\hline & $\geq 35$ & 31 & 10.2 \\
\hline \multirow{3}{*}{ Religion } & Orthodox & 269 & 88.8 \\
\hline & Muslim & 32 & 10.6 \\
\hline & Protestant & 2 & 0.7 \\
\hline \multirow{2}{*}{ Residence } & Urban & 190 & 62.7 \\
\hline & Rural & 113 & 37.3 \\
\hline \multirow{2}{*}{ Marital status } & Married & 297 & 98 \\
\hline & Unmarried & 6 & 2 \\
\hline \multirow{3}{*}{ Maternal education } & Not formal education & 146 & 48.2 \\
\hline & Grades 1-8 & 53 & 17.5 \\
\hline & High school and more & 104 & 34.3 \\
\hline \multirow{5}{*}{ Maternal occupation } & Housewives & 225 & 74.3 \\
\hline & Government employee & 48 & 15.8 \\
\hline & Merchant & 22 & 7.3 \\
\hline & Farmer & 1 & 0.3 \\
\hline & Daily laborer & 5 & 2.3 \\
\hline \multirow{4}{*}{ Husband occupation } & Farmer & 114 & 38.4 \\
\hline & Government employee & 90 & 30.3 \\
\hline & Merchant & 85 & 28.6 \\
\hline & Daily laborer & 8 & 2.7 \\
\hline \multirow{4}{*}{ Monthly income } & $\leq 1000$ & 100 & 33 \\
\hline & $1001-2000$ & 30 & 9.9 \\
\hline & $2001-3000$ & 33 & 10.9 \\
\hline & $\geq 3001$ & 140 & 46.2 \\
\hline
\end{tabular}

2.9. Data Collection Tools and Procedures. The data was collected by using semistructured interviewer-administrated questionnaires and patient charts. Questionnaires were developed in English. For interview purpose, questionnaires were translated first into Amharic and then back to English for its consistency. Four midwifery students in each ward were allocated for data collection purpose. Participants were interviewed by the data collectors after completion of examination.

2.10. Data Quality Control. The quality of data was assured by proper designing of the questionnaires. Half day training was given for data collectors. Every day after data collection, questionnaires were reviewed and checked for completeness by the data collector and principal investigator.

2.11. Data Processing and Analysis. All the questionnaires were checked, entered to Epi-info 7, and coded into SPSS version 20 software package for analysis. The degree of association between independent and dependent variables was assessed using odds ratio with 95\% confidence interval. The results were presented in the form of tables, figures, and text using frequencies, and summary statistics such as percentage and logistic regression was used.

\section{Results}

A total of 303 women have responded to the questionnaires making a response rate of $100 \%$. The age of the study participants was between 15 and 50 years with mean age of 26.41 \pm 5.27 years. The majority of the participants $(88.8 \%)$ were orthodox Christians, 98\% of them were married, and nearly half of the study participants (48.2\%) had never attended formal education.

Among the participants, 225 (74.3\%) were house wives, $114(38.4 \%)$ of their husbands were farmers in occupation, and $33 \%$ of the study participants' monthly incomes were less than or equal to 1000 EBR birr (Table 1).

3.1. Past Obstetric-Related Characteristics of Study Participants. Among the 303 study participants, 6.6\% had previous history of caesarean section and $3.0 \%, 2 \%$, and $3.3 \%$ had previous history of $\mathrm{APH}, \mathrm{PPH}$, and $\mathrm{PIH}$, respectively. Nearly three-fourth of the study participants, $65.7 \%$, 


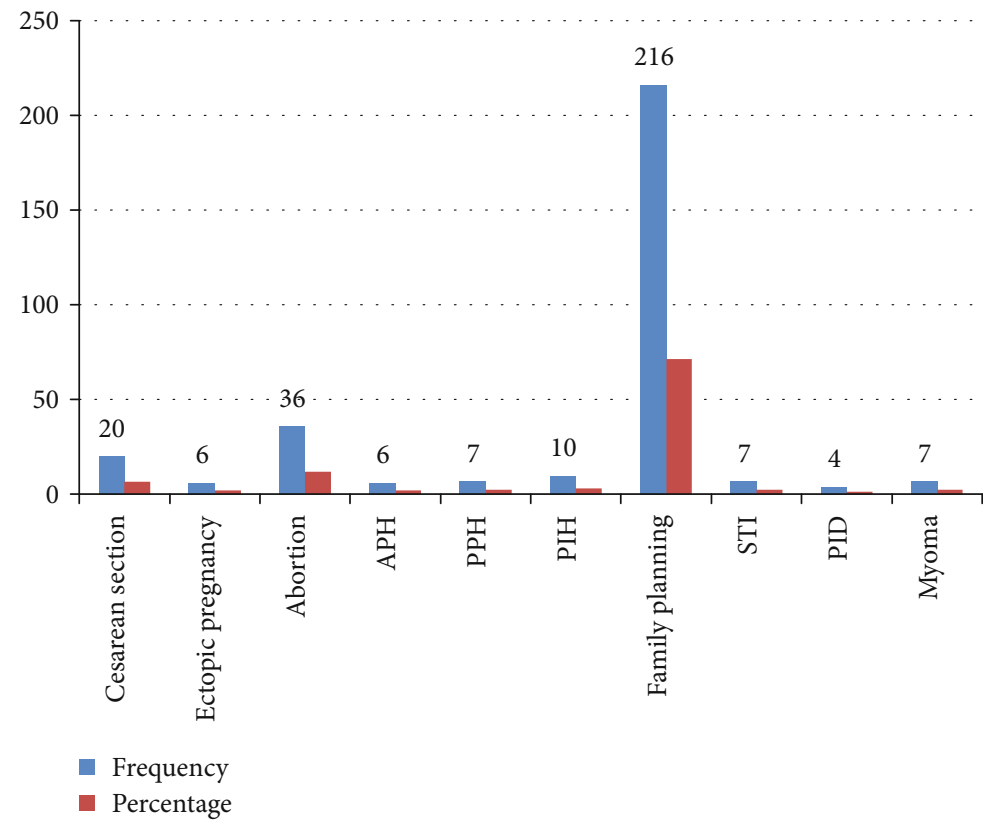

Figure 1: Past obstetric-related characteristics respondents at the University of Gondar Referral Hospital, Northwest Ethiopia, June 2019.

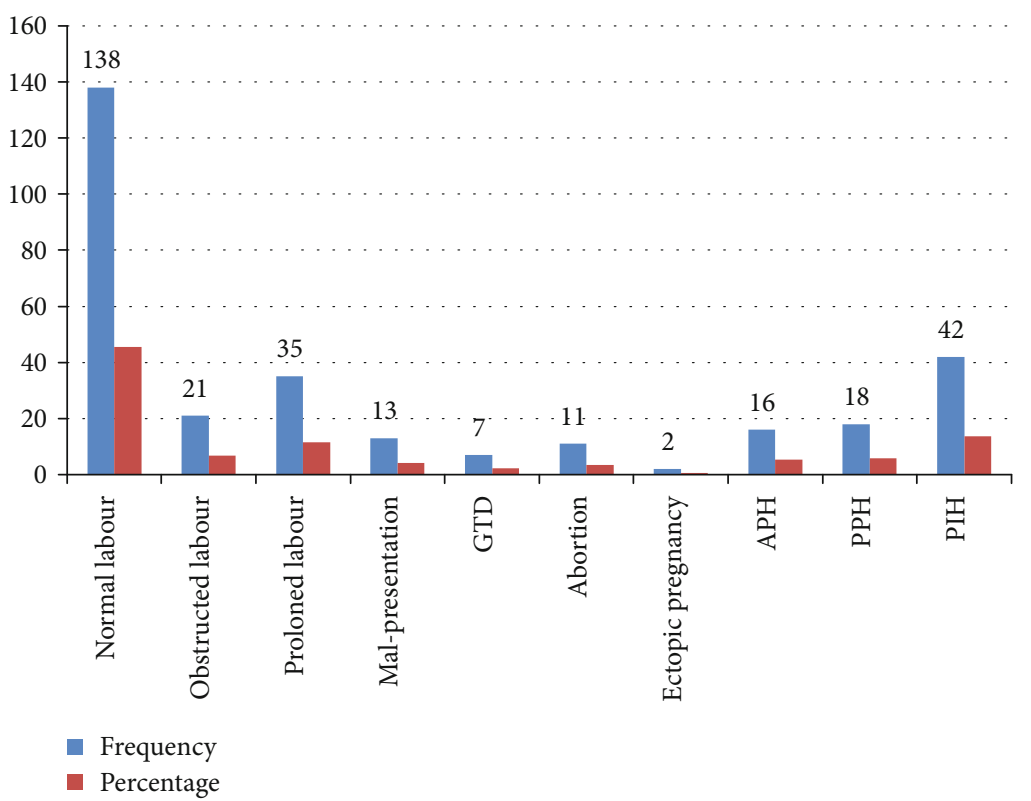

FIGURE 2: Initial admission diagnosis characteristics of respondents at the University of Gondar Referral Hospital, Northwest Ethiopia, June, $2019(n=303)$.

had family planning utilization history, and $11.9 \%$ of them had abortion history (Figure 1).

3.2. Current Obstetric-Related Characteristics of Study Participants. Nearly half, 149 (49.2\%), of the study participants had two to four children while 121 (39.9\%) of them had only one child. Among the study participants, 267 $(88.1 \%)$ of mothers had attended antenatal care and 253 $(83.5 \%)$ of the gestational age were term.

3.3. Maternal Health Service-Related Characteristics. Nearly half of the women, $50.8 \%$, had been referred. The majority,
$96.4 \%$, of the study participants were tested for hematocrit, and $72.79 \%$ of them had greater than $33 \%$. The suggested reasons why they seek the services were $36.6 \%$ due to labor pain, $13.5 \%$ due to prolonged labor, and 61 (20.1\%) of the respondents were due to vaginal bleeding. On the other hand, $45.5 \%, 6.9 \%$, and $13.8 \%$ of the respondents were admitted with an initial diagnosed of normal labor, obstructed labor, and pregnancy-induced hypertension, respectively (Figure 2 ).

One hundred sixty-seven (60\%) women had spontaneous vaginal deliveries. On the other hand, $11.5 \%$ of study participants delivered by cesarean section. In addition to this, 


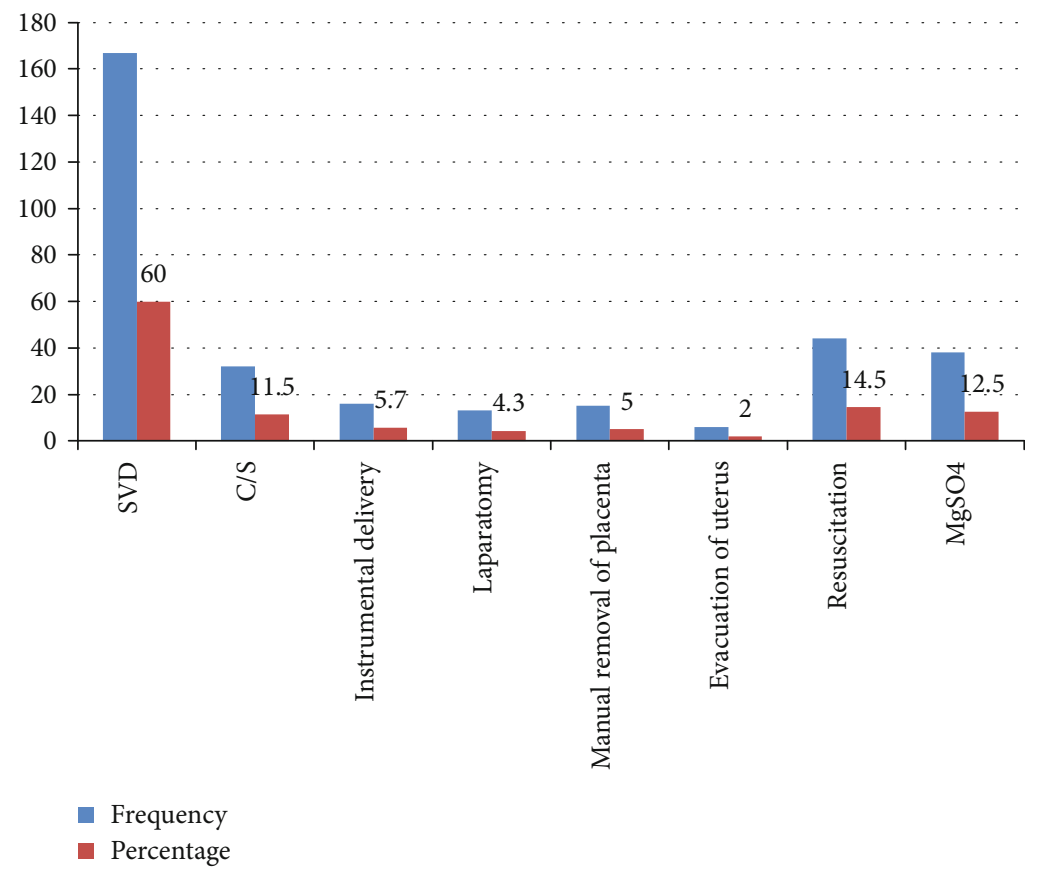

FIgURE 3: Type of intervention that was given to respondents at the University of Gondar Referral Hospital, Northwest Ethiopia, June, 2019 $(n=303)$.

$12.5 \%$ of study participants were treated with magnesium sulphate (MgSO4) (Figure 3).

3.4. Three Delay Model-Related Variables of Respondents. Two hundred two study participants (80\%) came to the hospital by their own decision. Delay in decision to seek care occurred in 48 (15.8\%) women. The most common reason why they were delayed to reach the hospital was $16(61.53 \%)$ due to lack of transport. One hundred sixtyseven $(55.1 \%)$ respondents reported transport greater than or equal to one hour to reach the health facility (Table 2).

3.5. Proportion of Maternal Near-Miss. The present study revealed that the estimated proportion of maternal nearmiss was $15.8 \%(95 \% \mathrm{CI}=11.9 \%-20.1 \%)$ by WHO criteria.

3.6. Factor Associated with Maternal Near-Miss. In bivariate binary logistic regression, residence, income, parity, duration of hospital stay, admission mode, visual disturbance, severe headache, vaginal bleeding, and pregnancy-induced hypertension $(\mathrm{PIH})$ were directly associated with maternal nearmiss. However, in the adjusted analyses, monthly income, duration of hospital stay, vaginal bleeding, and pregnancyinduced hypertension factors were significantly associated with maternal near-miss.

In this study, the odds of developing maternal near-miss among women who had lowest $(\leq 1000$ ETB) monthly income were 3.99 times than those who had greater than or equal to 3001 ETB per month $(\mathrm{AOR}=3.99,95 \% \mathrm{CI}=1.65-9.65)$.

In the current study, the odds of developing maternal near-miss among women who stayed seven and more days in hospital were 5.43 than those women who stayed less than seven days in the hospital $(\mathrm{AOR}=5.43,95 \% \mathrm{CI}=$
2.49-11.83). The study also suggested that women who presented with vaginal bleeding were 2.75 times more likely to develop maternal near-miss as compared to those who did not have vaginal bleeding $(\mathrm{AOR}=2.75,95 \% \mathrm{CI}$ $=1.17-6.47)$. Lastly, the analysis showed that the odds of developing maternal near-miss among women with pregnancy-induced hypertension were 5.13 than those who did not have PIH $(\mathrm{AOR}=5.13,95 \% \mathrm{CI}=2.08-12.6)$ (Table 3$)$.

\section{Discussion}

The aim of this study was to determine the proportion and factors associated with maternal near-miss at the University of Gondar Referral Hospital in 2019.

The present study revealed that the proportion of maternal near-miss at the University of Gondar Referral Hospital was $15.8 \%(95 \% \mathrm{CI}=11.9 \%-20.1 \%)$. This finding is comparable with a study conducted in Nigeria $17.4 \%$ [6] and Morocco $12 \%$ [18]. This similarity might be somewhat similar with sociodemographic characteristics of study participants. However, it is higher than a study done in Kerala $9.27 \%$ [13]; Harare, Zimbabwe 9.3\% [19]; and Brazil 10.2\% [20]. The variation might be as a result of the fact that the study institution is a tertiary hospital that receives complicated cases from remote primary hospitals and health centers within the zone and surrounding zones of the region. The second possible reason might be that in this study, $37.3 \%$ of the participants were from rural communities. This might be also correlated with delay of life-saving interventions which may impact maternal near-miss. Moreover, the last reason might be that, because of the limited facilities at the private hospitals, women with complicated pregnancies are not usually referred to these health institutions. 
TABLE 2: Three delay model-related characteristics of study participants at the University of Gondar Referral Hospital, Northwest Ethiopia June, $2019(n=303)$.

\begin{tabular}{|c|c|c|c|}
\hline Three delay model variables & & Frequency & Percent \\
\hline \multirow{3}{*}{ Decision maker } & Self & 239 & 78.9 \\
\hline & Husband & 48 & 15.8 \\
\hline & Relatives & 16 & 5.3 \\
\hline \multirow{2}{*}{ Delay in making decision } & Yes & 48 & 15.8 \\
\hline & No & 255 & 84.2 \\
\hline \multirow{2}{*}{ Did you go straight to the hospital? } & Yes & 277 & $91.4 \%$ \\
\hline & No & 26 & $8.58 \%$ \\
\hline \multirow{3}{*}{ Why you were delayed to reach the hospital? } & Lack of transport & 16 & 61.53 \\
\hline & Lack of money & 4 & 15.38 \\
\hline & Bad road construction & 6 & 23.07 \\
\hline \multirow{2}{*}{ Time to reach the hospital } & $<1 \mathrm{hr}$ & 136 & 44.9 \\
\hline & $\geq 1 \mathrm{hr}$ & 167 & 55.1 \\
\hline \multirow{2}{*}{ Time it take to get the care in the hospital } & $<30$ & 180 & 59.4 \\
\hline & $\geq 30$ & 123 & 40.6 \\
\hline \multirow{4}{*}{ Type of problems you faced in the hospital } & Delay in making correct diagnosis & 7 & 2.3 \\
\hline & No assessment by senior health care provider & 3 & 1.0 \\
\hline & Lack of supply and equipment & 4 & 1.3 \\
\hline & Poor monitoring of patient & 5 & 1.7 \\
\hline
\end{tabular}

In contrast, this study is lower as compared with the studies conducted in South Sudan 94.1\% [21], Northeast Region of Brazil 31.5\% [22], Southeast Iran 25.2\% [8], Brazilian demographic health survey 21.1\% [23], and Debre-Markos hospital, Ethiopia, 29.7\% [23]. The primary possible explanation might be due to the small sample size and short study period in the current study. The second reason might be due to the implementation of currently endorsed nonpneumatic antishock garment for postpartum hemorrhage management at the University of Gondar Referral Hospital. Lastly, it could be due to the availability of magnesium sulphate for prevention of eclampsia and broad spectrum antibiotics for the prevention of sepsis at the University of Gondar Referral Hospital.

The current study found that those mothers who had the lowest income $(\leq 1000$ ETB) per month were 3.99 times more likely to develop maternal near-misses as compared to their counter parts. This study is consistent with a study conducted in the Kathmandu Medical College of Teaching Hospital [24] and Muzaffarnagar, India [25]. This might be due to financial constraints that women face, leading to delays in access care, even when they have obstetric complications. The lack of economic power may make women dependent on the decision-making of others, even to access health care services.

The study also revealed that those women who stayed 7 or more days at the hospital were 2.49 times more likely to develop maternal near-misses than those who stayed less than 7 days. This finding is consistent with studies conducted in Amhara regional state hospitals [11]. This might be due to participants who had a longer hospital stay that could be at a higher risk of infection development. One contributing factor to this might be surgical site infections which commonly occur from the first few weeks after operation which might be related to the lack of aseptic technique with procedures, equipment, and inadequate postoperative care.

The study suggested that the odds of developing maternal near-miss among women who had vaginal bleeding were 2.75 times more likely to develop life-threatening complication as compared to their counter parts. This report is supported with studies conducted in Nepal [10], southeast Iran [8], and Tigray, Ethiopia [12]. The possible explanation might be that women with excessive blood loss are more susceptible to shock with treatment regimens which often required blood transfusion. Hemorrhage can occur suddenly and unexpectedly. Management of obstetric hemorrhage at facilities where there is no available blood supply and no highly trained health care workers who are skilled with management of obstetric hemorrhage may increase the morbidity of women with bleeding.

This study showed that women who had initially diagnosed with pregnancy-induced hypertension were 5.3 times more likely to develop maternal near-miss than those without pregnancy-induced hypertension. This is consistent with the study done in Kathmandu Hospital [24]; Tigray, Ethiopia [12]; Sudan [21]; and southeast Iran [8].This might be a reflection of poor management of pregnancy-induced hypertension cases in the peripheral health centers as $50.8 \%$ of them were referral cases. On the other hand, this might be due to delay in seeking appropriate treatment because of lack of proper referral system and early detection of lifethreatening conditions like eclampsia. 
TABLE 3: Factors associated with maternal near-miss at the University of Gondar Referral Hospital, Northwest Ethiopia, June 2019 ( $n=303$ ).

\begin{tabular}{|c|c|c|c|c|c|}
\hline \multirow{2}{*}{ Variables } & & \multicolumn{2}{|c|}{ Near-miss } & \multirow{2}{*}{ COR $(95 \% \mathrm{CI})$} & \multirow{2}{*}{$\operatorname{AOR}(95 \% \mathrm{CI})$} \\
\hline & & Yes $(\%)$ & No (\%) & & \\
\hline \multirow{2}{*}{ Residence } & Urban & $22(11.6)$ & $168(88.4)$ & 1 & \\
\hline & Rural & $26(23.0)$ & $87(77.0)$ & $0.01(1.22-4.26)$ & \\
\hline \multirow{4}{*}{ Monthly income } & $\leq 1000$ & $29(29.0)$ & $71(71)$ & $3.99(1.95,8.16)$ & $3.99(1.65,9.65)^{*}$ \\
\hline & $1001-2000$ & $2(6.7 \%)$ & $28(93.3)$ & $0.69(0.15,3.26)$ & $0.89(0.14,5.57)$ \\
\hline & $2001-3000$ & $4(12.1)$ & $29(87.9)$ & $1.34(0.41,4.43)$ & $1.65(0.41,6.67)$ \\
\hline & $\geq 3001$ & $13(9.3)$ & $127(90.7)$ & 1 & 1 \\
\hline \multirow{3}{*}{ Parity } & 1 & $18(14.2)$ & $109(85.8)$ & 1 & \\
\hline & $2-4$ & $23(15.4)$ & $126(84.6)$ & $1.10(0.56,2.15)$ & \\
\hline & $\geq 5$ & $7(25.9)$ & $20(74.1)$ & $2.11(0.87,5.73)$ & \\
\hline \multirow{2}{*}{ Duration of hospital stay } & $<7$ days & $22(9.3)$ & $215(90.7)$ & 1 & \\
\hline & $\geq 7$ days & $26(39.4)$ & $40(60.6)$ & $6.4(3.28,12.30)$ & $5.43(2.49,11.83)^{* *}$ \\
\hline \multirow{2}{*}{ Admission mode } & Not referred & $16(10.7)$ & $133(89.3)$ & 1 & \\
\hline & Referred & $32(20.8)$ & $122(79.2)$ & $2.18(1.14,4.17)$ & \\
\hline \multicolumn{6}{|l|}{ Reason for seeking care } \\
\hline \multirow{2}{*}{ Visual disturbance } & Yes & $17(50)$ & $17(50)$ & $7.68(3.56,16.56)$ & \\
\hline & No & $31(11.5)$ & $238(88.5)$ & 1 & \\
\hline \multirow{2}{*}{ Severe headache } & Yes & $16(42.1)$ & $22(57.9)$ & $5.29(2.52,11.12)$ & \\
\hline & No & $32(12.1)$ & $233(87.9)$ & 1 & \\
\hline \multirow{2}{*}{ Vaginal bleeding } & Yes & $18(29.5)$ & $43(70.5)$ & $2.96(1.51,5.78)$ & $2.75(1.17,6.47)^{* *}$ \\
\hline & No & $30(12.4)$ & $212(87.6)$ & 1 & \\
\hline \multicolumn{6}{|l|}{ Initial diagnosis } \\
\hline \multirow{2}{*}{$\mathrm{PIH}$} & Yes & $18(42.9)$ & $24(57.1)$ & $5.77(2.81,11.86)$ & $5.13(2.08,12.63)^{* *}$ \\
\hline & No & $30(11.5)$ & $231(88.5)$ & 1 & \\
\hline
\end{tabular}

NB: ${ }^{*} p$ value $<0.005$ and ${ }^{* *} p<0.05$.

\section{Conclusion}

The proportion of maternal near-miss was found to be high. Variables like low monthly income, seven or more days of hospital stay, vaginal bleeding, and pregnancy-induced hypertension were significantly associated factors with maternal near-miss.

5.1. Recommendation. Early identification and management of vaginal bleeding, pregnancy-induced hypertension, and decrement of long hospital stay are recommended to the hospital. Lastly, income generation activity needs attention by region.

5.2. Limitation of the Study. In this study, no follow-up was done for the women after their discharge from the hospital. This may be underestimating the magnitude of maternal near-miss.

\section{Abbreviations}

AOR: Adjusted odds ratio

APH: Antepartum hemorrhage
CI: Confidence interval

CS: Caesarean section

EDHS: Ethiopian demographic health survey

ETB: Ethiopian birr

GTD: Gestational troplastic disease

HCT: Hematocrit

HIV: Human immune-virus

MDG: Millennium development goal

MNM: Maternal near-miss

PID: Pelvic inflammatory disease

PIH: Pregnancy-induced hypertension

PPH: Postpartum hemorrhage

SDG: Sustainable development goal

SPSS: Statistical package for the social science

STI: Sexually transmitted infection

SVD: Spontaneous vaginal delivery

WHO: World Health Organization.

\section{Data Availability}

The data will be available from the corresponding author when appropriate at the requesting time. 


\section{Ethical Approval}

It was obtained from the Institutional Review Board (IRB) of the University of Gondar on behalf of the Ethical Review Committee of School of Midwifery. A letter of cooperation was obtained from the Gondar referral hospital administrator.

\section{Consent}

The reasons why the research was to be done was explained to the study subjects; verbal informed consent was obtained from each study subject after explanation of the purpose of the study, and involvement (to be participant) was after their complete consent.

\section{Conflicts of Interest}

The author declare that there is no competing interest.

\section{Authors' Contributions}

MMA wrote the proposal, participated in data collection, analyzed the data, and drafted the paper. MMA read, edited, and approved the final manuscript.

\section{Acknowledgments}

The author is very grateful to the University of Gondar for the approval of the ethical clearance. My last gratitude goes to the Gondar referral hospital administrator. I would like to extend my appreciation to the study participants and data collectors.

\section{References}

[1] J. P. Souza, J. G. Cecatti, S. M. Haddad et al., "The WHO maternal near-miss approach and the maternal severity index model (MSI): tools for assessing the management of severe maternal morbidity," PLoS One, vol. 7, no. 8, p. e44129, 2012.

[2] K. Begum, "Maternal near miss: an indicator for maternal health and maternal care," Journal of Bangladesh College of Physicians and Surgeons, vol. 36, no. 1, pp. 1-3, 2018.

[3] R. Pattinson, L. Say, J. P. Souza, Broek Nv, C. Rooney, and WHO Working Group on Maternal Mortality and Morbidity Classifications, "WHO maternal death and near-miss classifications," Bulletin of the World Health Organization, vol. 10.1186/s12978-016-0232-y, no. 10, p. 734, 2009.

[4] E. Nelissen, E. Mduma, J. Broerse et al., "Applicability of the WHO maternal near miss criteria in a low-resource setting," PLoS One, vol. 8, no. 4, article e61248, 2013.

[5] WHO, UNICEF, UNFPA, World Bank Group and the United Nations Population Division, Trends in maternal mortality: 1990 to 2015, WHO, 2015, WHO Library Cataloguing-inPublication Data.

[6] O. P. Aduloju, T. Aduloju, and O. M. Ipinnimo, "Profile of maternal near miss and determinant factors in a teaching hospital, Southwestern Nigeria," International Journal of Reproduction, Contraception, Obstetrics and Gynecology, vol. 7, no. 9, pp. 3450-3458, 2018.
[7] F. C. Oliveira Jr., M. L. Costa, J. G. Cecatti, J. L. Pinto e Silva, and F. G. Surita, "Maternal morbidity and near miss associated with maternal age: the innovative approach of the 2006 Brazilian demographic health survey," Clinics, vol. 68, no. 7, pp. 922-927, 2013.

[8] T. Naderi, S. Foroodnia, S. Omidi, F. Samadani, and N. Nakhaee, "Incidence and correlates of maternal near miss in Southeast Iran," International Journal of Reproductive Medicine, vol. 2015, Article ID 914713, 5 pages, 2015.

[9] A. K. Tura, J. Zwart, J. van Roosmalen, J. Stekelenburg, T. van den Akker, and S. Scherjon, "Severe maternal outcomes in eastern Ethiopia: application of the adapted maternal near miss tool," PLoS One, vol. 13, no. 11, article e0207350, 2018.

[10] B. S. Gurung, R. B. Koju, and Y. Dongol, "Near-miss obstetric events in a tertiary care teaching hospital in Nepal: an audit," Nepal Journal of Obstetrics and Gynaecology, vol. 19, no. 1, pp. 30-35, 2015.

[11] T. Abate, M. Dile, and T. Syoum, "Proportion of maternal near misses and associated factors in referral hospitals of Amhara regional state, Northwest Ethiopia: institution based cross sectional study," Gynecology \& Obstetrics, vol. 5, no. 8, pp. 1-8, 2015.

[12] D. E. Mekango, M. Alemayehu, G. B. Gebregergs, A. A. Medhanyie, and G. Goba, "Determinants of maternal near miss among women in public hospital maternity wards in northern Ethiopia: a facility based case-control study," PLoS One, vol. 12, no. 9, article e0183886, 2017.

[13] R. P. Reena and K. R. Radha, "Factors associated with maternal near miss: a study from Kerala," Indian Journal of Public Health, vol. 62, no. 1, pp. 58-60, 2018.

[14] Government of Ethiopia et al., Demographic and Health Survey, Central Statistical Agency, 2016.

[15] A. Langer, A. Meleis, F. M. Knaul et al., "Women and health: the key for sustainable development," The Lancet, vol. 386, no. 9999, pp. 1165-1210, 2015.

[16] S. Z. Brown, H. Newby, D. Chou et al., "Understanding global trends in maternal mortality," International Perspectives on Sexual and Reproductive Health, vol. 39, no. 1, pp. 32-41, 2013.

[17] T. E. Yarinbab, "Delays in utilization of institutional delivery service and its determinants in Yem Special Woreda, Southwest Ethiopia: health institution based cross-sectional study," Journal of Gynecology and Womens Health, vol. 10, no. 4, pp. 1-6, 2018.

[18] B. Assarag, B. Dujardin, A. Delamou, F.-Z. Meski, and V. De Brouwere, "Determinants of maternal near-miss in Morocco: too late, too far, too sloppy?," PLoS One, vol. 10, no. 1, article e0116675, 2015.

[19] H. Chikadaya, M. G. Madziyire, and S. P. Munjanja, "Incidence of maternal near miss in the public health sector of Harare, Zimbabwe: a prospective descriptive study," BMC Pregnancy and Childbirth, vol. 18, no. 1, p. 458, 2018.

[20] R. M. Domingues, M. A. Dias, A. O. Schilithz, and M. D. Leal, "Factors associated with maternal near miss in childbirth and the postpartum period: findings from the birth in Brazil National Survey, 2011-2012," Reproductive Health, vol. 13, no. S3, article 115, 2016.

[21] F. M. Alemu, M. Fuchs, T. Martin Vitale, and M. Abdalla Mohamed Salih, "Severe maternal morbidity (near-miss) and its correlates in the world's newest nation: south sudan," International Journal of Women's Health, vol. 2019, pp. 177-190, 2019. 
[22] J. G. Cecatti, R. T. Souza, R. C. Pacagnella, M. C. Leal, E. C. Moura, and L. M. P. Santos, "Maternal near miss among women using the public health system in the Amazon and Northeast regions of Brazil," American Journal of Public Health, vol. 37, pp. 232-238, 2015.

[23] M. Gedefaw, H. Gebrehana, A. Gizachew, and F. Taddess, "Assessment of maternal near miss at Debre Markos referral hospital, Northwest Ethiopia: five years experience," Journal of Epidemology, vol. 4, no. 4, pp. 199-207, 2014.

[24] N. S. Shrestha, R. Saha, and C. Karki, "Near miss maternal morbidity and maternal mortality at Kathmandu Medical College Teaching Hospital," Kathmandu University Medical Journal, vol. 8, no. 30, pp. 222-226, 2010.

[25] S. Tyagi, "Near miss maternal mortality, who is responsible? Administration, healthcare system or the people themselves," International Journal of Reproduction, Contraception, Obstetrics and Gynecology, vol. 6, no. 10, pp. 4318-4322, 2017. 